\title{
Features of Contact Wire Wear and Measures for Local Wear on Simple Catenary with Copper-Steel Contact Wire
}

\section{Mizuki TSUNEMOTO}

Researcher,

\section{Satoshi HARADA}

Assistant Senior Researcher,
Masatoshi SHIMIZU

Senior Researcher,

Contact Line Structures, Power Supply Technology Division

A simple catenary with copper-steel contact wire is one of overhead contact lines equipped high-speed lines as Shinkansen. Local wear of the contact wires were visible at the simple catenary with copper-steel contact wire of commercial lines. In addition, the result of the investigation on this line revealed that the wear occurred at overlaps of the overhead contact line and a part of station. The authors therefore proposed a measure for local wear at the overlaps, and verified the effects on a commercial line. Furthermore, we clarified the cause of wear by monitoring the sliding surfaces of the contact wires at the stations.

Keywords: current collection, CS simple catenary, copper-steel contact wire, overlap, local wear, adhesive wear, simulation, Shinkansen

\section{Introduction}

A simple catenary with copper-steel contact wire (CS simple catenary) is overhead contact line for high-speed lines as Shinkansen opened after Nagano Shinkansen. CS simple catenary use CS110 $\left(111.1 \mathrm{~mm}^{2}\right)$ which is lightweight and high-strength copper-steel contact wire (CS contact wire). Thus, high-speed operation is made possible by raising a wave propagation velocity. Moreover, there are few lines as compared with hitherto known heavy compound catenary system, and since it is simple wire structure, it has the feature of being able to control construction costs ${ }^{1)}$

However, several years after installation, local wear of the contact wire were visible on CS simple catenary. Then, the authors investigated the data of contact wire wear obtained by inspection car to find the sites of local wear. The result of the investigation revealed that the local wear occurred at overlaps of the overhead contact line and some stations not provided with passing tracks. Then, we conducted a field detailed survey on the overlaps where local wear occurred, and examined the cause of local wear using the simulation etc. We therefore proposed measures for local wear at the overlaps, and verified the effects on a commercial line. Furthermore, we clarified the cause of wear at the stations by monitoring the sliding surfaces of the contact wires.

\section{Characteristics of contact wire wear of CS simple catenary}

\subsection{Identification of local wear sites from inspection data}

To identify the sites where local wear of contact wire occurred on CS simple catenary, the data of contact wire wear obtained by inspection car was classified the drum into the three parts as shown in Fig. 1.

(A) Entry-side wire of overlap as referred to line A

(B) Exit-side wire of overlap (line B)

(C) Other part of wire (general part)

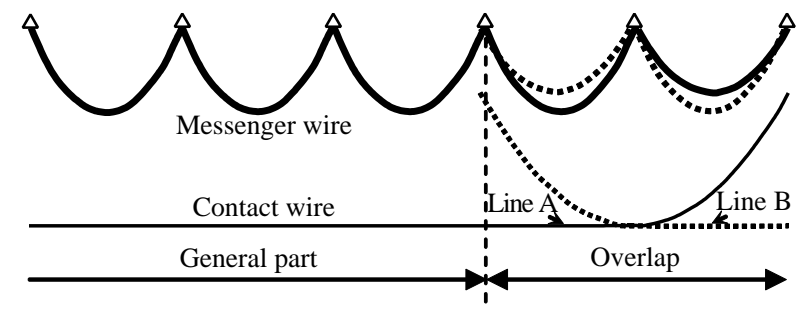

Fig. 1 Classification of drum

The authors investigated the distribution of maximum diameter wear of each part and the result normalized by average of a line installed CS simple catenary was as shown in Fig. 2. The larger value meant that local ware occurred more remarkably in the part. Consequently, though on most of drums maximum diameter wear of each part were almost identical, there were several drums that were remarkably large value on the line B. In addition, it turned out that wear adjacent to the station were large, especially the general part.

\subsection{Wear at overlaps}

It turned out that remarkable local wear occurred on the line B on CS simple catenary. Then, in order to examine the cause of the local wear, a field detailed survey on the overlaps was conducted with a measuring instrument, which was equipped laser sensor measuring the residual diameter and displacement sensor measuring the height of contact wires ${ }^{2}$. The instrument was able to measure the contact wire height and wear on the line A and the line B at the overlap, simultaneously. The measurement result was as shown in Fig. 3. Moreover, for comparison, the measurement result of heavy compound catenary system was as shown in Fig. 3. The lower wear waveform indicated that the more wear advanced. The pulses on the wear waveform were positions of hangers that connected contact wire with messenger wire. 


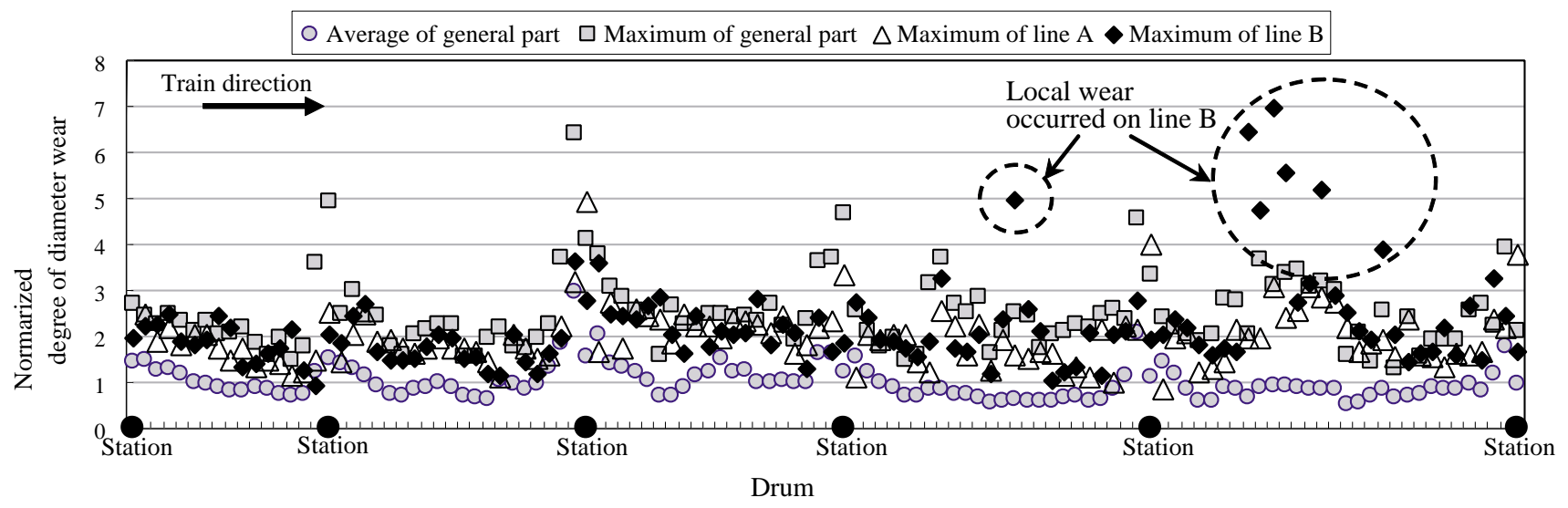

Fig. 2 Normalized degree of diameter wear

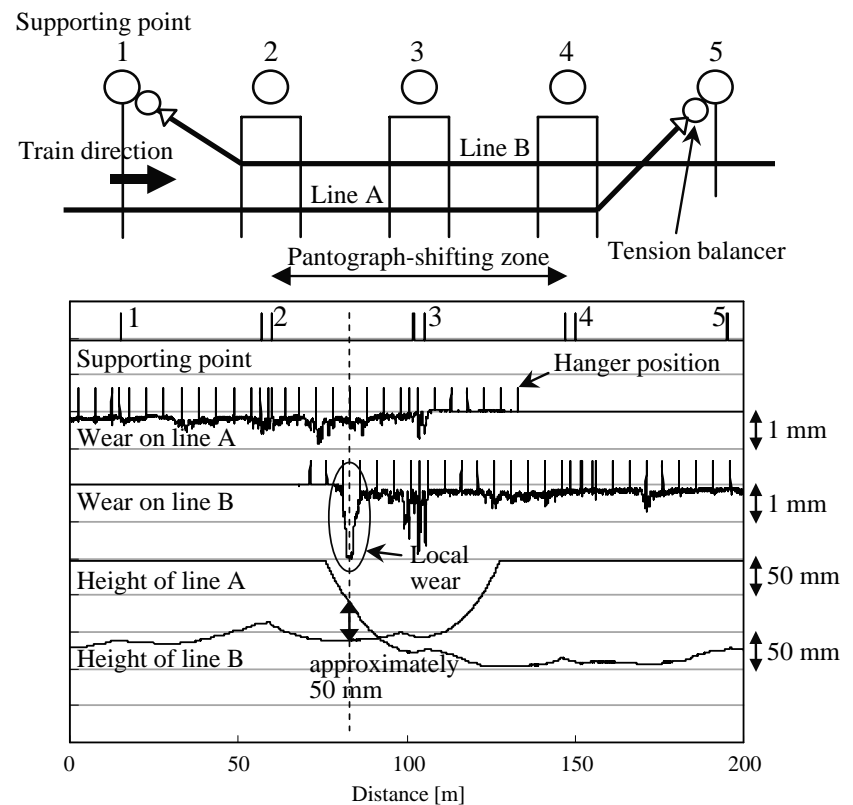

(a) CS simple catenary

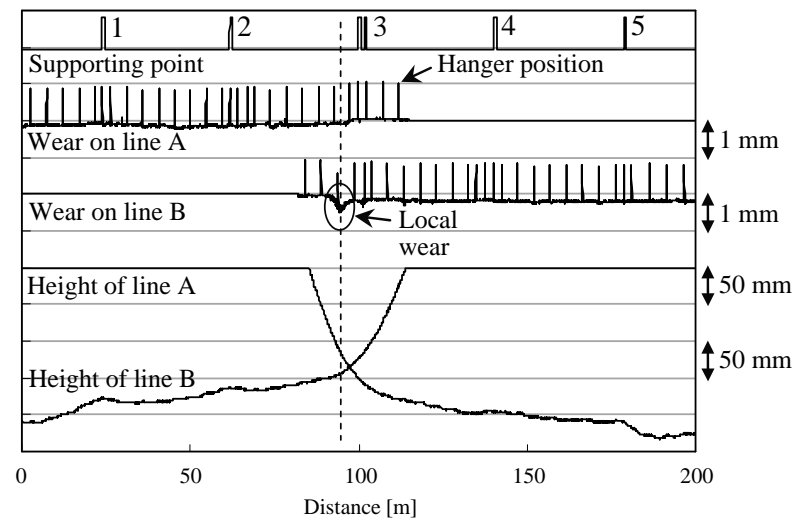

(b) Heavy compound catenary system

Fig. 3 Local wear at overlap

Figure 4 shows examples of overlap configurations: (a) Ordinary configuration

(b) Configuration $\mathrm{A}$, which has a different height between the line $\mathrm{A}$ and the line $\mathrm{B}$

(c) Configuration B, an initial point to rise respectively,

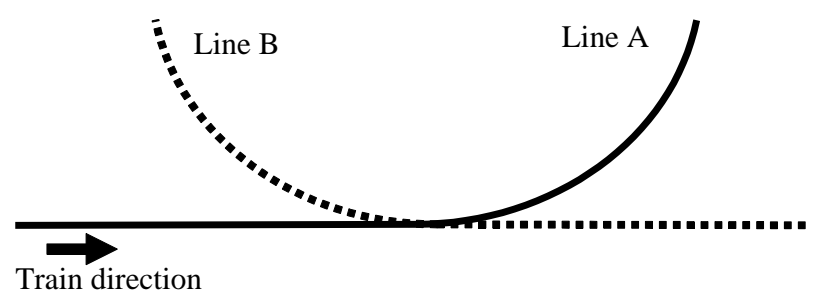

(a) Ordinary configuration

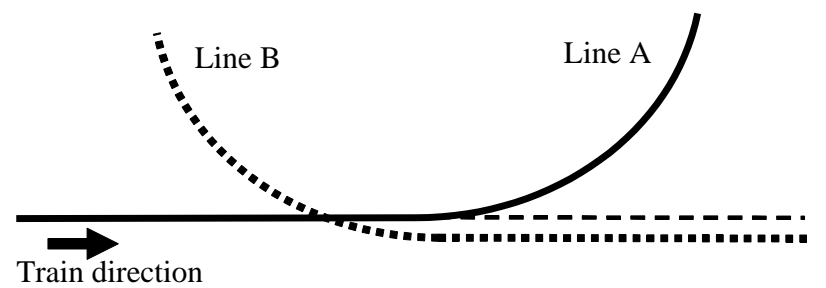

(b) Configuration $\mathrm{A}$

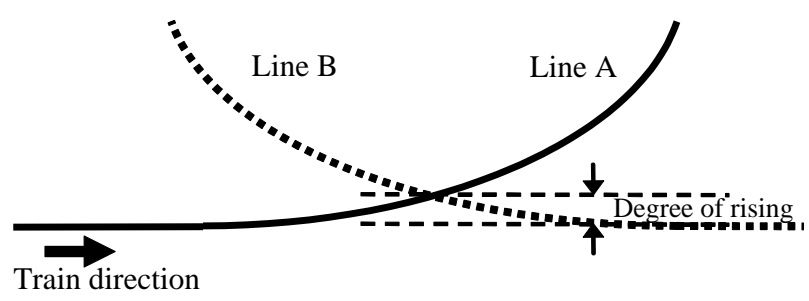

(c) Configuration B

Fig. 4 Example of overlap configurations

shifted forward and backward from the supporting point of the middle of overlap and an intersecting point of the line A and the line B was raise.

Figure 3 (a) and (b) showed the case of the configuration $\mathrm{B}$ that the line $\mathrm{B}$ was lower than the line $\mathrm{A}$ and the case of the configuration $\mathrm{C}$ that the line $\mathrm{B}$ was lower than the line A, respectively. The local wear likely occurred in both cases of the overlap configuration.

Many of local wear on CS simple catenary was occurred adjacent to the middle of span where was in front of the supporting point of the middle of an overlap (the supporting point 3 in Fig. 3). The local wear spot were located approximately $20 \mathrm{~m}$ short of the supporting point 3 from entry side, and up-and-down distance between the 
line $\mathrm{A}$ and the line $\mathrm{B}$ was approximately $50 \mathrm{~mm}$. The 50 $\mathrm{mm}$, it was mostly equivalent to the uplift of the middle of span that length was $50 \mathrm{~m}$ in case a train passed at a speed of $260 \mathrm{~km} / \mathrm{h}$, which maximum speed of the line installed CS simple catenary. Moreover, there was the feature that degree of the local wear approximately 2 $\mathrm{mm}$ was very large. On the other hand, local wear on heavy compound catenary system was occurred adjacent to the intersecting point of the line $\mathrm{A}$ and the line $\mathrm{B}$ where was adjacent to the supporting point of the middle of an overlap (supporting point 3 in Fig. 3). It was presumable that the increase of contact force between contact wires and pantographs led to local wear ${ }^{2)}{ }^{3)}$. For local wear in the heavy compound catenary system, a measure that was the configuration $\mathrm{B}$, which the line $\mathrm{B}$ was $20 \mathrm{~mm}$ higher than the line $\mathrm{A}$ in the pantograph-shifting zone was proposed, and the effect was reported ${ }^{2}$.

As mentioned above, the amount and generating spot of local wear was different in classification of overhead contact lines and overlap configurations. Since the whole of mass and tension of CS simple catenary was smaller than heavy compound catenary system, uplift by pantographs was large, consequently oscillation of overhead contact lines also become large. Therefore, in the site where up-and-down distance was too insufficient, contact force when second pantograph contacted the line B adjacent to the middle of span was presumable to be the main causes of local wear.

\subsection{Wear at stations}

Since lines installed CS simple catenary are comparatively low train density, there are, except main stations, many stations not provided with passing tracks. At the stations, both stopping and passing trains run on the main track. Therefore, if the roughness on sliding surface and local wear occurred, the current collection performance of a passing train may be affected. Thus, CS contact wire adjacent to the station was investigated in detail. The measurement result of residual diameter of contact wires, microscope pictures of sliding surfaces, and image processing of the pictures were as shown in Fig. 5. In approximately one $\mathrm{km}$ centering on the station, wear advanced, especially at pantograph stop positions. Moreover, as for the pictures of sliding surface, black and white parts were considered as the state attached lubricating component contained contact strip of a pantograph and as that unattached, respectively. The attachment rate of lubricating component to sliding surface was $37 \%$ in the pantograph stop position much lower compared to 70 to $94 \%$ of other parts. The average roughness ( $\mathrm{Ra}$ ) of sliding surface measured in approximately one $\mathrm{km}$ centering on a station was as shown in Table 1 . The number of the measuring points corresponded to Fig. 5. In the pantograph stop position which wear was especially advancing, Ra was approximately nine $\mu \mathrm{m}$, and it was larger than approximately two $\mu \mathrm{m}$ of other parts. Similar to the wear occurred in compound catenary system, the main causes of the wear at the station was presumed that lubricating

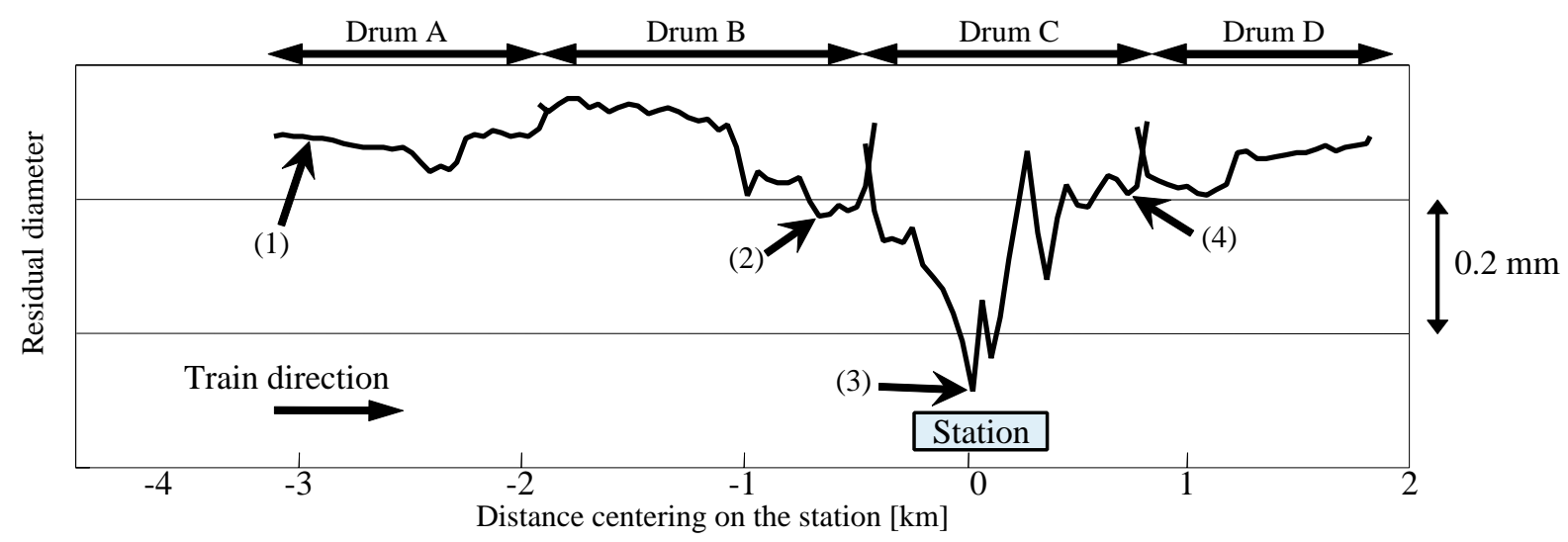

(a) Residual diameter of contact wire

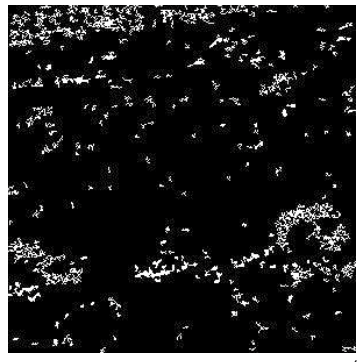

(1) Attachment rate: $94 \%$

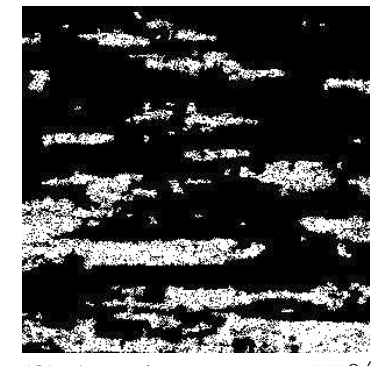

(2) Attachment rate: $77 \%$

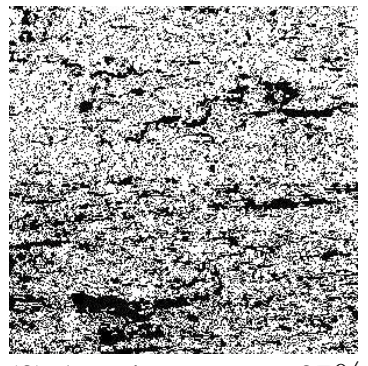

(3) Attachment rate: $37 \%$

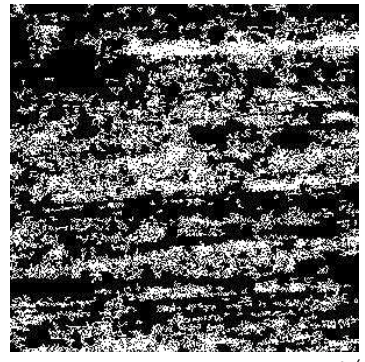

(4) Attachment rate: $70 \%$

(b) State of sliding surfaces (after image processing)

*The numbers in parentheses corresponded to the measuring points

Fig. 5 Wear and attachment rate of sliding surface adjacent to the station 
component contained contact strip was insufficient supplied to the sliding surface, and then adhesive wear progressed. Although the method of supplying lubricant oil using feeder device proposed as this measure, the implementation at the stations was conceivable to be difficult that oil may be splatter on a home for passing train. Therefore, a measure from a material side such as use of low-wear contact wires etc. would be required.

Table 1 Average roughness of sliding surface

\begin{tabular}{c|c}
\hline Measuring point & Average roughness Ra $[\mu \mathrm{m}]$ \\
\hline$(2)$ & 2.05 \\
\hline$(3)$ & 9.13 \\
\hline$(4)$ & 1.99 \\
\hline
\end{tabular}

\section{Numerical analyses of overlap configuration}

As mentioned above, the main causes of local wear at overlaps were that up-and-down distance between the line A and the line B at hoist part of the middle of overlaps was too close, and at the kind of sites contact force was very large if second pantograph contact the line B that were oscillating by first pantograph. Therefore, avoidance of contact of pantograph with the line B adjacent to the middle of span at entry-side of overlap and suppression of oscillation by head pantograph, it became the basic principles of measures. Then, the authors conducted computational simulation of overhead contact line and pantograph to consider the optimal overlap configuration for preventing local wear on CS simple catenary.

\subsection{Simulation condition}

The simulation condition of overhead contact line was a standard equipment of CS simple catenary, which contact wire was CS110 and messenger wire was PH150 and each tension was $19600 \mathrm{~N}$. Overlap configuration was two spans, and the span length was $45 \mathrm{~m}$. Dynamic model of pantograph was as shown in Fig. 6. Considering the train running on the line installed CS simple catenary, the number of pantograph was two, $50 \mathrm{~m}$ interval, and running velocity was 260,280 and $300 \mathrm{~km} / \mathrm{h}$.

We verified the following configurations to avoid the contact of pantograph with the line B adjacent to the center of span at the entry-side of the overlap that was the basic principle of measures to local wear:

(1) Ordinary configuration (Fig. 4 (a))

(2) Configuration A as shown in Fig. 4 (b), which line B was $20 \mathrm{~mm}$ lower than line A

(3) Configuration A which line B was $20 \mathrm{~mm}$ higher than line A

(4) Configuration B as shown in Fig. 4 (c): the degree of raising was $15 \mathrm{~mm}$

(5) Configuration $\mathrm{B}$, the degree of raising was $25 \mathrm{~mm}$

(6) Configuration $\mathrm{B}$, the degree of raising was $35 \mathrm{~mm}$

The configuration (1) was ordinary configuration of overlap. The configuration (2) was as proposed as a measure for local wear for heavy compound catenary system. For comparative purpose, we also verified the con- figuration (3). Since remarkably large contact force likely generated at an intersecting point of the line $\mathrm{A}$ and the line $\mathrm{B}$, the configuration $\mathrm{B}$ had to set the degree of raising to approximately $10 \mathrm{~mm}$ or less on heavy compound system 2). However, the configuration $B$ that the degree of raising was 15,25 and $35 \mathrm{~mm}$ was verified since it was possible that the up-and-down distance between the line $\mathrm{A}$ and the line $\mathrm{B}$ adjacent to the middle of span at entry-side of overlap was sufficient on CS simple catenary. In addition, the up-and-down distance of all configurations of this simulation designed $100 \mathrm{~mm}$ or more to avoid contact of pantograph with the line B.

\subsection{Measured items for simulation}

Measured items for the simulation were as follows:

(1) Contact force between contact wire and pantograph

(2) Oscillating amplitude of contact wire

(3) Contact loss ratio

The measuring zone to the above-mentioned measured item and measuring points were as shown in Fig. 7.

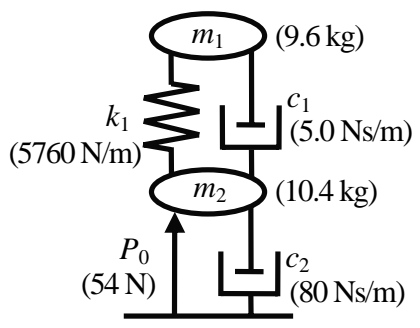

Fig. 6 Dynamic model of pantograph

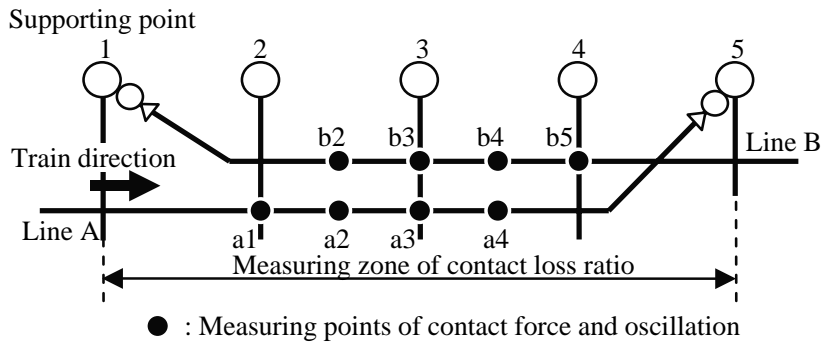

Fig. 7 Measuring zone and points of the simulation

\subsection{Overlap configuration preventing local wear}

\subsubsection{Contact force}

The maximum contact force between the line B and pantographs was as shown in Fig. 8 (a). The configurations (2) and (6) were large, and it might become maximum value more than $200 \mathrm{~N}$. On the configuration (2), the maximum contact force generated adjacent to the middle of span at entry-side of overlap, and it was consistent with the part which local wear occurred on a commercial line. Moreover, the ordinary configuration (1) was generated large contact force approximately $170 \mathrm{~N}$ in the identical part as the configuration (2) at speeds of 280 $\mathrm{km} / \mathrm{h}$ or more. The maximum contact force on the configurations (3) and (5) were smaller than on the ordinary configuration (1) at a speed of $260 \mathrm{~km} / \mathrm{h}$. 


\subsubsection{Oscillating amplitude adjacent to the middle of span}

Since oscillating amplitude of the line A was comparable on all configurations, oscillating amplitude of the line $B$ adjacent to the middle of span, which were the measuring points b2 and b4 in Fig. 7, was as shown in Fig. 8 (b) and (c). Oscillating amplitude of entry-side measuring point b2 in the case of the configuration (2) was largest, approximately $70 \mathrm{~mm}$. In the case of the configuration (1), that was also comparatively large, approximately $47 \mathrm{~mm}$. It was attributed to the fact that oscillation of the line B was large, since pantograph shifted from the line A to the line B adjacent to the middle of the span on these configurations. Oscillating amplitude of the line B on other configurations was small, so it showed that pantograph did not contact adjacent to the measurement point b2. Oscillating amplitude of the exit-side measurement point b4 in the case of the configuration (3) was largest, approximately $75 \mathrm{~mm}$. Because of structural feature of the configuration (3), pantograph head rose while shifting from the line A to the line B, therefore oscillation was large.

\subsubsection{Contact loss}

Since contact loss of first pantograph did not occur in any configurations, contact loss ratio occurring on second pantograph was as shown in Fig. 8 (d). Except for the configurations (3) and (6), contact loss did not occur in other configurations. The configurations (3) and (6) were presumably affected by oscillation of the line B.

Considering all of the measured items, the configuration (5) was the optimal overlap configuration for preventing local wear on CS simple catenary.

\section{Application and verification on a commercial Line}

\subsection{Application to commercial line}

As the result of verification of the simulation, the configuration (3), which the intersecting point of the line A and the line $\mathrm{B}$ was raised up to $25 \mathrm{~mm}$, did not generate remarkably large contact force, so it was an optimal configuration for preventing local wear. Therefore, overlap was adjusted as the configuration (3) on a commercial line where local wear occurred, and the effects of preventing local wear was verified.

The results of measurement of contact wire height, wear before, and after adjustment were as shown in Fig. 9 . At a local wear generating point adjacent to the middle of span of entry-side overlap, up-and-down distance of the line $\mathrm{A}$ and the line $\mathrm{B}$ was $100 \mathrm{~mm}$ or more. It was sufficient that avoid contact pantograph with the line $\mathrm{B}$, and the degree of raising at the intersecting point of the line $A$ and the line B was approximately $25 \mathrm{~mm}$. Therefore, the adjustment of overlap configuration was as designed.

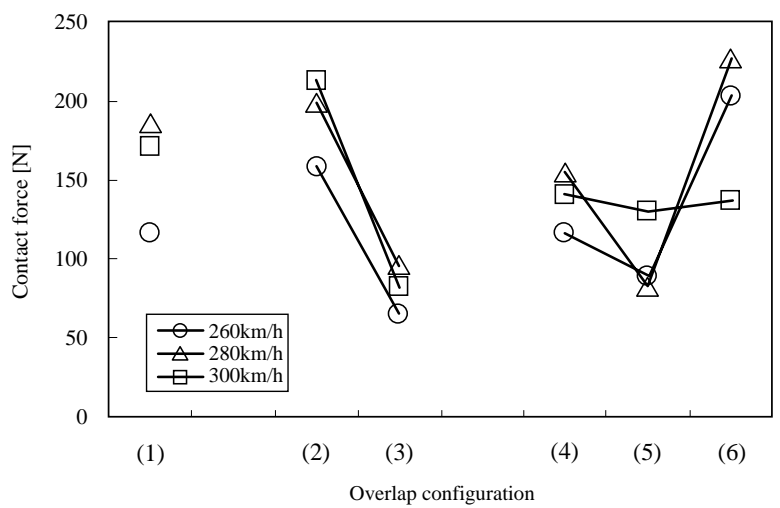

(a) Contact force between line B and second pantograph

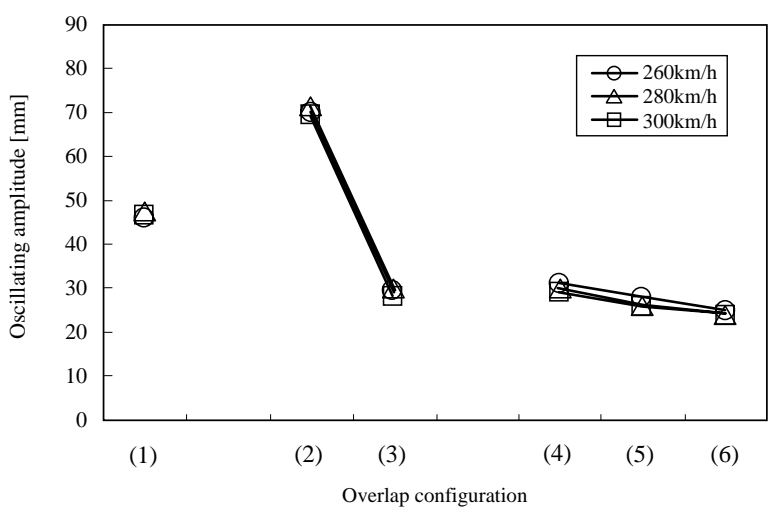

(b) Oscillation amplitude of measuring point b2

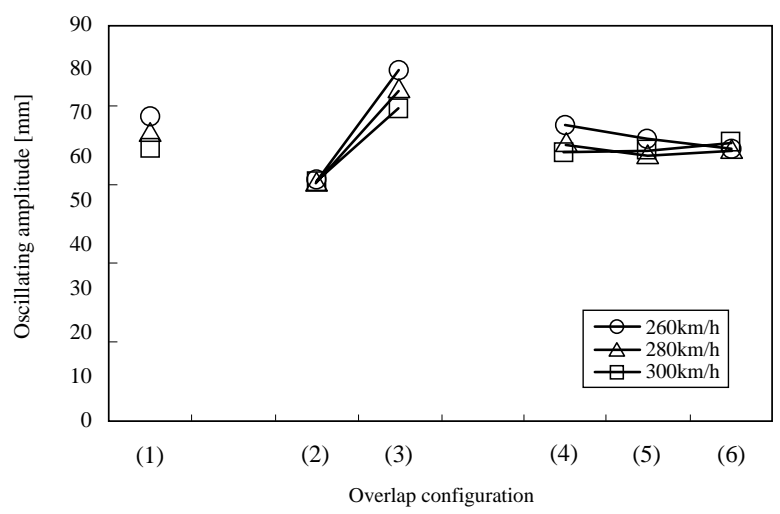

(c) Oscillation amplitude of measuring point b4

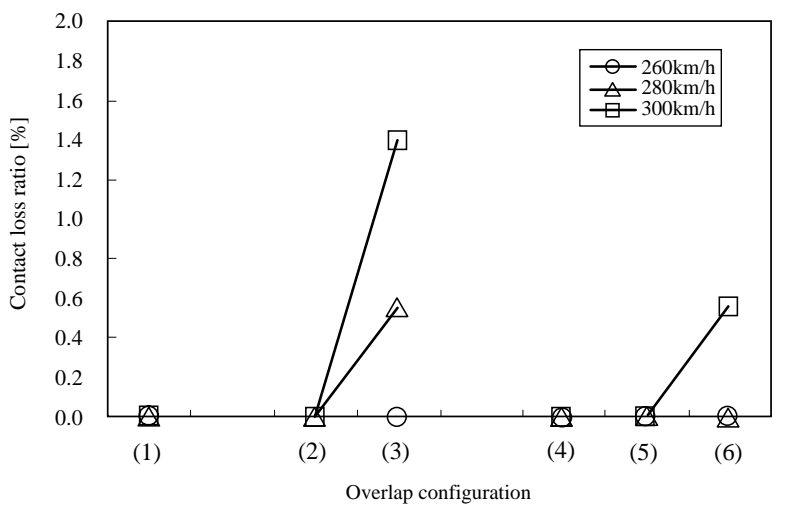

(d) Contact loss ratio of second pantograph

Fig. 8 Simulation results 


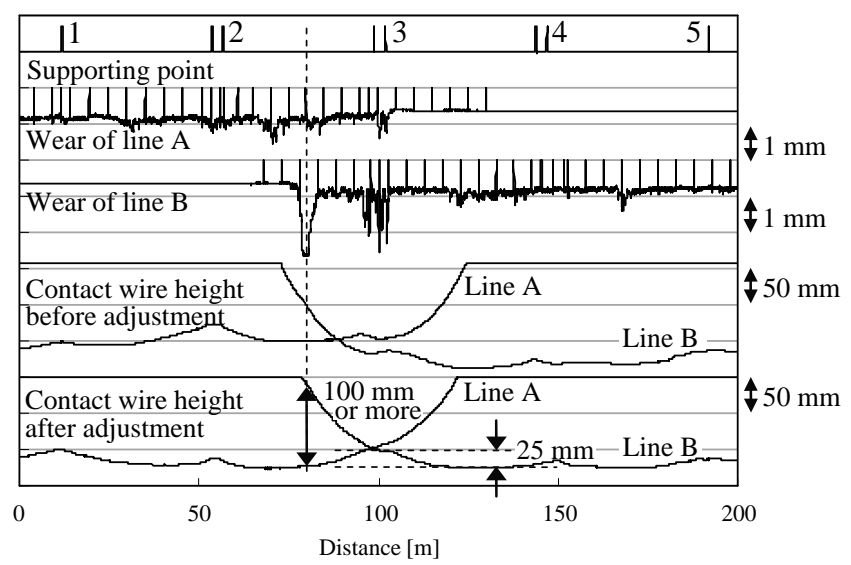

Fig. 9 Contact wire height before and after adjustment

\subsection{Verification of effect of measurement}

The authors continuously conducted measurements of wear to verify the effect to prevent local wear until five months after the adjustment. The results of the measurement were as shown in Fig. 10. Comparing the waveforms of the wear of immediately after the adjustment and those of 5-month later, there was no progressive wear visible at local wear. Also, there was no progressive wear visible at the intersecting point of the line A and the line B where a large contact force likely generate, therefore, the effect of measurement was verified.

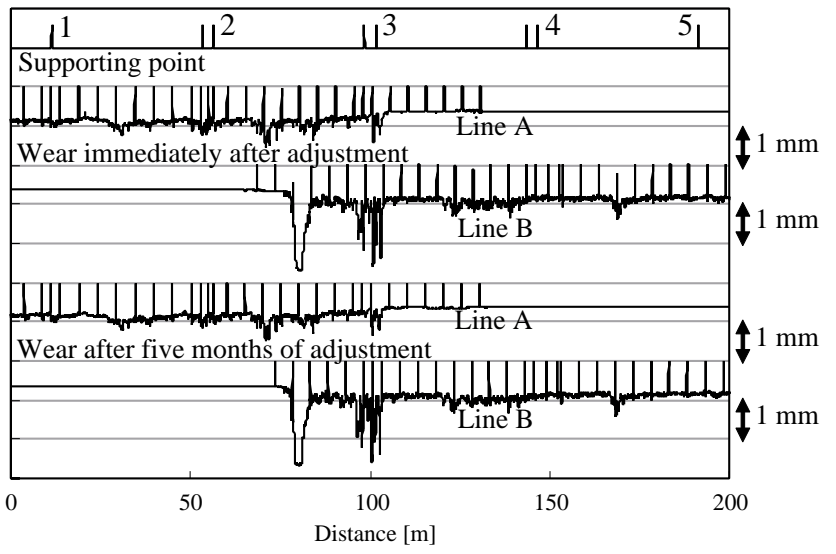

Fig. 10 Wear progress after adjustment

\subsection{Verifying shift state of pantograph at overlap}

In order to investigate the state while pantograph shifting from the line A to the line B at the overlap before and after adjustment, the data of contact wire wear obtained by inspection car was investigated. The results of the measurement were as shown in Fig. 11. Before adjustment, since pantograph shifted to the line B in front of the supporting point 3 , it was presumable that the line B largely oscillated by pantograph. On the other hand, after adjustment, because of pantograph shifting adjacent to the supporting point 3 , it was presumable that the line B did not largely oscillate.

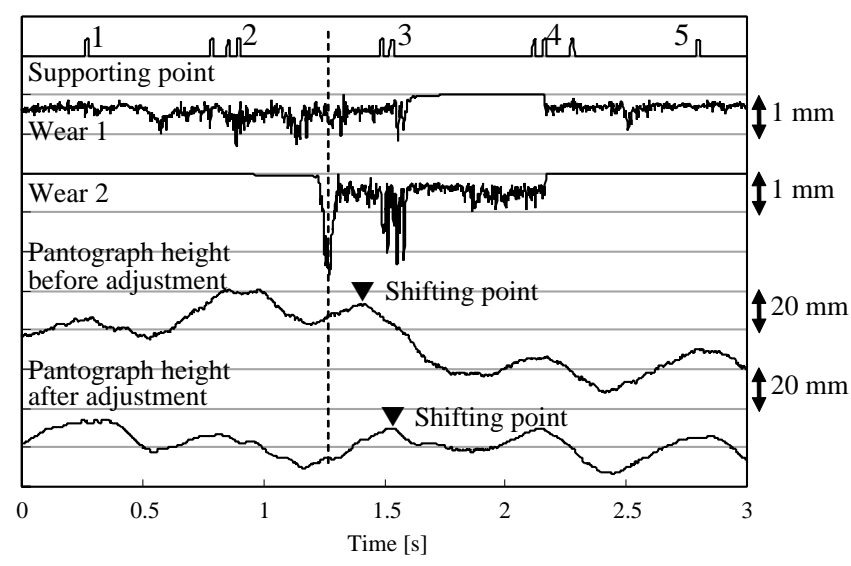

Fig. 11 The state of pantograph running overlap (First pantograph of inspection car)

\section{Conclusions}

With respect to local wear on CS simple catenary, the authors verified the cause, proposed a measure, and summarized the following results:

(1) At overlaps, main cause of local wear was that remarkably large contact force generated since up-and-down distance between contact wires was insufficient.

(2) At stations not provided with passing tracks, main cause of the local wear was that lubricating component contained contact strip insufficiently supplied to sliding surface of contact wires, and then adhesive wear progressed.

(3) As the simulation result, we proposed optimal configurations to prevent local wear, and verified the effect on a commercial line. We planned to carry out the measurement on a commercial line continuously at the overlaps.

\section{Acknowledgment}

The authors would like to express sincere appreciation to personnel involved in East Japan Railway Company: JR East Technical Center, Nagano branch Electric Power Division and Nagano Electric Power Technical Center.

\section{References}

1) Aboshi, M. Nakai, I., Tsuburaya, T., and Kaneko, M., "Development of Overhead Simple Catenary System for Projected Shinkansen," RTRI Report, Vol. 9, No. 9, pp. 37-42, 1995 (in Japanese)

2) Shimizu, M., and Fujii, Y., "The Most Suitable Structure of Contact Wire on Overlap Sections of Shinkansen Lines," RTRI Report, Vol. 9, No. 9, pp. 1924, 1995 (in Japanese)

3) Shimizu, M., Harada, S., and Mandai, T., "Measures to Prevent Wearing of Contact Wires in Overlap Sections on Shinkansen Lines," RTRI Report, Vol. 17, No. 7, pp. 19-24, 2003 (in Japanese) 